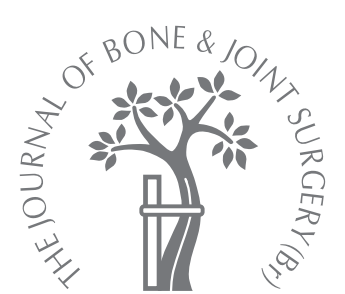

A. Gupta

From Maulana Azad Medical College, New Delhi, India

\title{
The management of ununited fractures of the femoral neck using internal fixation and muscle pedicle periosteal grafting
}

\author{
We describe a series of 20 patients with ununited fractures of the femoral neck following \\ neglected trauma or failed primary internal fixation who were seen at a mean of 7.5 months \\ (2 to 18) following injury. Open reduction and internal fixation of the fracture was \\ performed in all patients, together with a myoperiosteal flap on the quadratus femoris \\ muscle pedicle. \\ Union occurred at a mean of 4.9 months (2 to 10) in all patients. The mean follow-up was \\ for 70 months (14 to 144). There was no further progression in six of seven patients with \\ pre-operative radiological evidence of osteonecrosis of the femoral head. One patient had \\ delayed collapse and flattening of the femoral head ten years after union of the fracture, but \\ remained asymptomatic.
}

This study demonstrates the orthopaedic application of myoperiosteal grafting for inducing osteogenesis in a difficult clinical situation.

The concept of periosteal grafting is more than a century old. ${ }^{1}$ The osteogenic potential of free periosteum may be controversial, ${ }^{2-5}$ but the vascularised periosteal flap has proved to have excellent osteogenic capacity ${ }^{6-10}$ and has been used to prefabricate a vascularised bone graft in conjunction with a structural matrix and recombinant human bone morphogenetic protein-2 in a rat model. ${ }^{11,12}$ Vascularised bone grafting rotated on a muscle pedicle such as quadratus femoris, ${ }^{13,14}$ gluteus medius, ${ }^{15,16}$ tensor fascia lata or sartorius, ${ }^{15,17}$ is an established method of treatment. Similarly a periosteal flap rotated on a muscle pedicle should provide good osteogenesis, although this has not been generally applied. ${ }^{18}$

The treatment of nonunion of a femoral neck fracture in a young patient is challenging. The problem may be compounded by concomitant osteonecrosis of the femoral head. ${ }^{19-21}$ Whereas hemiarthroplasty or total hip replacement (THR) is the treatment of choice in older patients, it is undesirable in young adults because of concerns about subsequent revision. It is therefore preferable to salvage the femoral head in younger patients. The treatment of nonunion of the femoral neck includes valgus osteotomy ${ }^{22-24}$ where shearing forces are converted into compression forces, non-vascularised bone grafting, 2,25,26 muscle pedicle bone grafting ${ }^{13,14}$ and vascularised bone grafting. ${ }^{27,28}$ This study aimed to explore the osteogenic potential of periosteal grafting in the treatment of this condition in younger patients.

\section{Patients and Methods}

We studied 20 patients with ununited fractures of the femoral neck treated between 1988 and 2005 with open reduction and internal fixation, combined with quadratus femoris myoperiosteal grafting. There were four female and 16 male patients with a mean age of 24 years ( 10 to 40). The mean interval between the injury and the reconstructive surgery was 7.5 months (2 to 18). A total of 18 patients presented with neglected trauma and two had previous internal fixation. An anteroposterior radiograph of the involved hip with the limb in $15^{\circ}$ of internal rotation was obtained for all patients and assessed for various 'union at risk' signs which include a) osteonecrosis of the femoral head in the form of diffuse or localised osteolysis, sclerosis, cysts or flattening; b) severe overriding of the fracture ends, with the lesser trochanter lying at a level higher than the inferior articular surface of the femoral head and c) complete absorption of the femoral neck on either side of the fracture. A classification based on these risk signs for failure to unite was developed. Type 0 is nonunion with no 'at-risk' signs; type 1 is a nonunion with any one of the three 'at-risk' signs; type 2 has any two of the three 'at-risk' 
Table I. Demographic details of the patients

\begin{tabular}{|c|c|c|c|c|c|c|c|c|c|c|c|}
\hline Case & $\begin{array}{l}\text { Age } \\
\text { (yrs) }\end{array}$ & Gender & $\begin{array}{l}\text { Category } \\
\text { at risk }\end{array}$ & $\begin{array}{l}\text { Pre-operative } \\
\text { Steinberg } \\
\text { grade }\end{array}$ & $\begin{array}{l}\text { Duration of } \\
\text { nonunion } \\
\text { (mths) }\end{array}$ & $\begin{array}{l}\text { Primary } \\
\text { treatment }\end{array}$ & $\begin{array}{l}\text { Internal } \\
\text { fixation }\end{array}$ & $\begin{array}{l}\text { Method of post- } \\
\text { operative } \\
\text { immobilisation }\end{array}$ & $\begin{array}{l}\text { Time to } \\
\text { union } \\
\text { (mths) }\end{array}$ & $\begin{array}{l}\text { Steinberg grade } \\
\text { at final follow-up }\end{array}$ & $\begin{array}{l}\text { Duration of } \\
\text { follow-up } \\
\text { (mths) }\end{array}$ \\
\hline 1 & 13 & $\mathrm{M}$ & $1 \mathrm{a}$ & II & 3 & None & Knowles pins & Plaster spica & 3 & II & 44 \\
\hline 2 & 14 & M & $1 a$ & II & 6 & None & Knowles pins & Plaster spica & 3 & 0 & 64 \\
\hline 3 & 34 & $M$ & $2 b c$ & 0 & 18 & None & Knowles pins & Plaster spica & 6 & 0 & 58 \\
\hline 4 & 12 & $\mathrm{~F}$ & $2 a b$ & III & 5 & None & Knowles pins & Plaster spica & 2 & 0 & 42 \\
\hline 5 & 14 & $\mathrm{~F}$ & $1 b$ & 0 & 5 & None & $\begin{array}{l}\text { Cancellous } \\
\text { screws }\end{array}$ & Thomas splint & 4 & 0 & 78 \\
\hline 6 & 20 & $\mathrm{M}$ & $1 a$ & III & 18 & None & Knowles pins & Thomas splint & 7 & 0 & 58 \\
\hline 7 & 16 & M & 0 & 0 & 2 & None & Knowles pins & Thomas splint & 4 & 0 & 84 \\
\hline 8 & 35 & M & $2 a b$ & III & 18 & None & Knowles pins & Thomas splint & 7 & III & 144 \\
\hline 9 & 32 & M & $0^{*}$ & 0 & 10 & $\mathrm{ORIF}^{\dagger}$ & Knowles pins & Plaster spica & 7 & IV & 118 \\
\hline 10 & 30 & $\mathrm{M}$ & $1 b$ & 0 & 6 & None & $\begin{array}{l}\text { Cancellous } \\
\text { screws }\end{array}$ & Thomas splint & 4 & 0 & 117 \\
\hline 11 & 10 & M & $1 a$ & II & 5 & None & Knowles pins & Thomas splint & 2 & 0 & 76 \\
\hline 12 & 35 & M & $1 b$ & 0 & 8 & None & $\begin{array}{l}\text { Cancellous } \\
\text { screws }\end{array}$ & Thomas splint & 10 & 0 & 52 \\
\hline 13 & 20 & M & 0 & 0 & 2 & None & $\begin{array}{l}\text { Cancellous } \\
\text { screws }\end{array}$ & Thomas splint & 4 & 0 & 98 \\
\hline 14 & 27 & $\mathrm{M}$ & $1 \mathrm{a}$ & II & 6 & None & $\begin{array}{l}\text { Cancellous } \\
\text { screws }\end{array}$ & Thomas splint & 5 & 0 & 90 \\
\hline 15 & 35 & $\mathrm{M}$ & $1 b$ & 0 & 8 & None & Knowles pins & Thomas splint & 5 & 0 & 97 \\
\hline 16 & 25 & $\mathrm{M}$ & $1 \mathrm{c}$ & 0 & 6 & None & $\begin{array}{l}\text { Cancellous } \\
\text { screws }\end{array}$ & Thomas splint & 5 & 0 & 91 \\
\hline 17 & 21 & $\mathrm{~F}$ & 0 & 0 & 2 & None & $\begin{array}{l}\text { Cancellous } \\
\text { screws }\end{array}$ & Thomas splint & 3 & 0 & 24 \\
\hline 18 & 12 & M & $1 b$ & 0 & 5 & None & Knowles pins & Thomas splint & 2 & 0 & 26 \\
\hline 19 & 40 & $\mathrm{M}$ & $0^{*}$ & 0 & 2 & $\mathrm{ORIF}^{\dagger}$ & Knowles pins & Thomas splint & 6 & 0 & 16 \\
\hline 20 & 38 & $F$ & $2 b c$ & 0 & 16 & None & Knowles pins & Thomas splint & 8 & 0 & 14 \\
\hline
\end{tabular}

* failed primary internal fixation

${ }^{\dagger} \mathrm{ORIF}$, open reduction internal fixation

signs; and type 3 has all three 'at-risk' signs. Type 1 is subdivided into $1 \mathrm{a}, 1 \mathrm{~b}$ and $1 \mathrm{c}$, and type 2 is subdivided into $2 \mathrm{ab}, 2 \mathrm{ac}$ and $2 \mathrm{bc}$ correlating with the particular 'at-risk' signs seen. The details of the patients are shown in Table I. Varying degrees of absorption of the femoral neck were seen in all patients. In seven there were pre-operative radiological signs of osteonecrosis of the femoral head (Steinburg classification: ${ }^{29}$ stage 2 in four patients and stage 3 in three). No MRI was available to substantiate the vascular status of the femoral head in the remaining patients. A total of 14 patients with more than $2 \mathrm{~cm}$ of true shortening of the limb had skeletal traction using $3 \mathrm{~kg}$ to $15 \mathrm{~kg}$ for three to five days pre-operatively in order to pull the greater trochanter down. In a further two patients aged 46 years and 48 years, respectively, it was not technically possible to elevate the periosteal flap because of its adherence to the bone, and therefore they were excluded from the study.

Operative technique. The anaesthetised patient is placed prone on the fracture table and the hip exposed using a posterior approach. The gluteus maximus muscle is split in the direction of its fibres and the sciatic nerve located and avoided. The quadratus femoris muscle is identified and the periosteum at its insertion on the femur delineated and incised approximately $0.5 \mathrm{~cm}$ beyond its insertion. The periosteum is elevated using a sharp periosteal elevator. The other short external rotators are divided close to their insertion and the hip capsule opened through a T-shaped inci- sion. The fracture site is exposed and all the interposed fibrous tissue excised. In the two patients with internal fixation, the existing implants were removed. In most patients it is not possible to achieve good appositional contact due to the irregular shape of the fragments and the associated absorption of the femoral neck. No attempt to improve contact between the fracture surfaces is made if it involves compromising the length of the femoral neck or the neckshaft angle. The distal fracture surface, which often is found to be sclerotic and smooth, is decorticated using a sharp osteotome and multiple drill holes. The fracture is aligned and fixed under direct vision using three Knowles pins (13 patients) or $6.5 \mathrm{~mm}$ cancellous screws (seven patients) inserted from the lateral femoral cortex below the greater trochanter. The quadratus femoris with the attached intact periosteum is now mobilised, rotated, brought over the fracture site posteriorly and stitched to the capsule and the surrounding tissues. The wound is closed in layers and the hip immobilised for approximately six weeks. Five patients treated early in the series were immobilised in a plaster hip spica and the remainder on a Thomas splint. Gentle hip exercises and non-weight-bearing mobilisation continued for a further six to eight weeks. Subsequently gradual progression from partial to full weight-bearing was advised, depending on clinical and radiological signs of fracture union. The patients were reviewed every six weeks until the fracture had united, then 


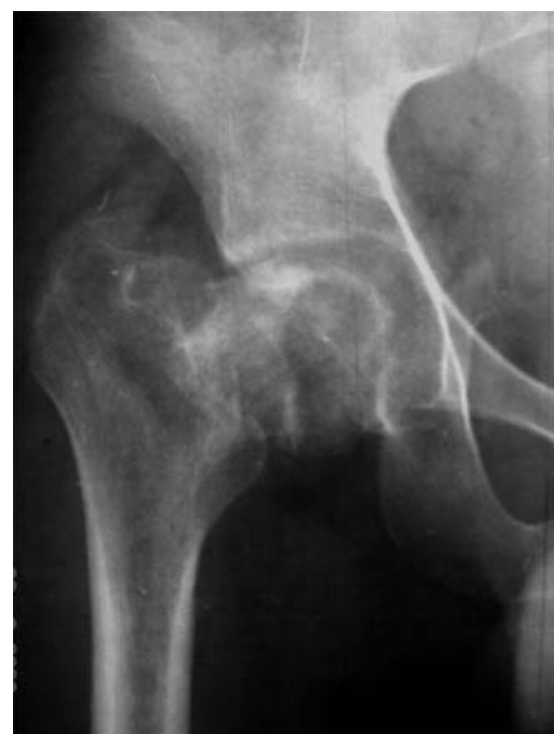

Fig. 1a

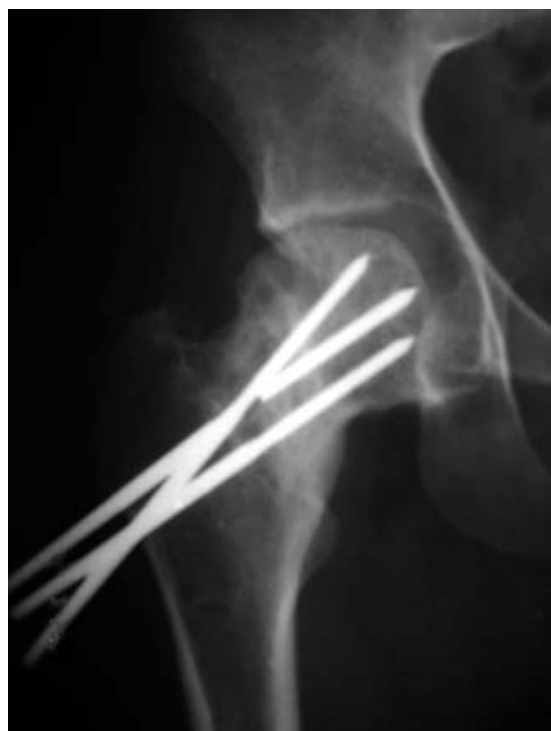

Fig. 1b

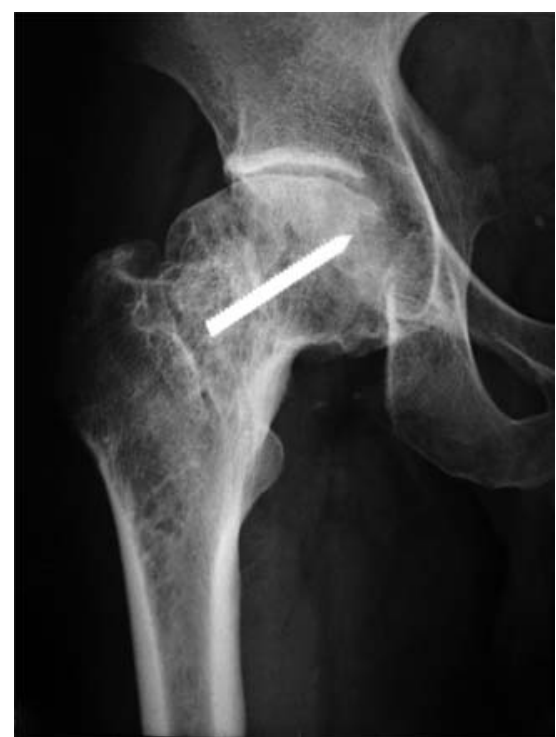

Fig. 1c

Figure 1a - Pre-operative radiograph of a 35-year-old patient with an 18-month-old type 2ab nonunion of the femoral neck. There is an area of increased radiodensity in the superolateral part of the head and a large radiolucent area in its medial part with an irregular and hazy articular margin medially. Figure $1 \mathrm{~b}$ - The fracture was fixed using three Knowles pins and a radiograph taken 36 months post-operatively shows union with good revascularisation of the femoral head. One of the Knowles's pins is broken. Coarse trabeculation is evident involving the whole head, but smooth articular margins are preserved. Figure 1c-Radiograph 12 years after surgery showing flattening of the femoral head and early osteoarthritic changes. The patient remained asymptomatic.

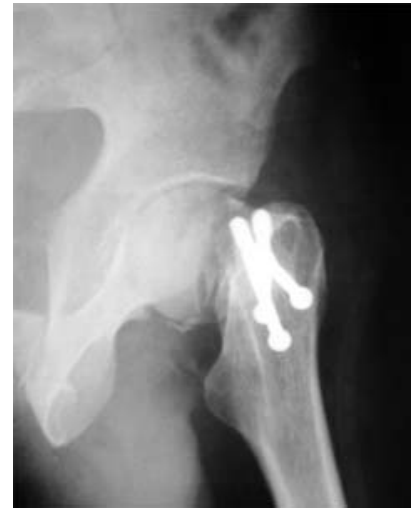

Fig. $2 a$

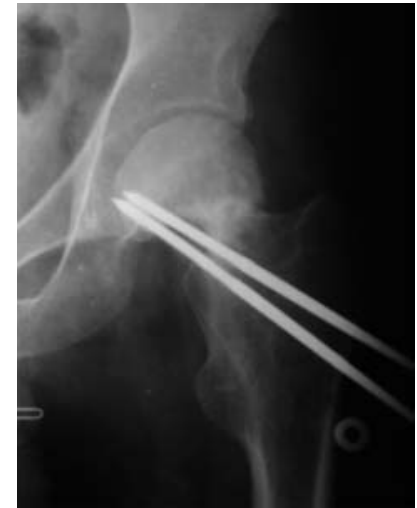

Fig. $2 b$

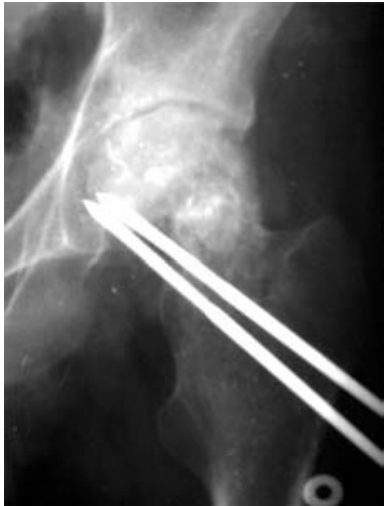

Fig. 2c

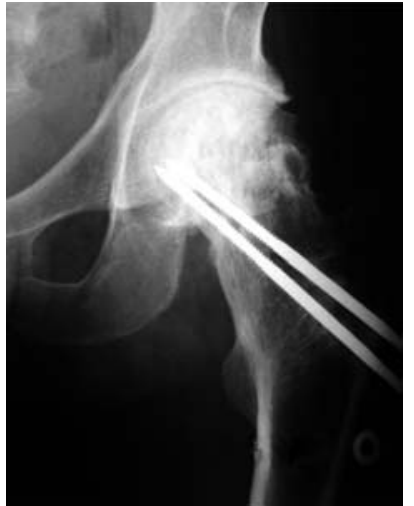

Fig. 2d

Figure $2 \mathrm{a}$ - Radiograph of a 32-year-old male ten months after failed primary osteosynthesis. Figure $2 \mathrm{~b}$ - Post-operative radiograph eight months after surgery showing fracture union despite very tenuous fixation. There is increased density involving the whole of the femoral head. Figure $2 \mathrm{c}-$ Radiograph at 20 months showing irregular articular margins with multiple lytic areas throughout the femoral head. Figure $2 \mathrm{~d}-\mathrm{Radiog} r a p h$ at ten years showing diffuse sclerosis of the femoral head with the pins in situ.

every three months for approximately one year and annually thereafter. In the absence of symptoms, most patients did not attend for annual review and were specifically recalled.

\section{Results}

The mean time to union of the fracture for all 20 patients was 4.9 months ( 2 to 10 ). This was confirmed clinically by the ability of the patient to bear full weight on the involved limb in the absence of pain, and on anteroposterior radiographs by complete obliteration of the fracture gap with or without sclerosis of the fracture margins. The mean follow-up was for 70 months (14 to 144). The mean Harris hip score (HHS) ${ }^{30}$ at the last follow-up was 93 (75 to 100). None of the seven patients with preoperative osteonecrosis of the femoral head had deterio- 


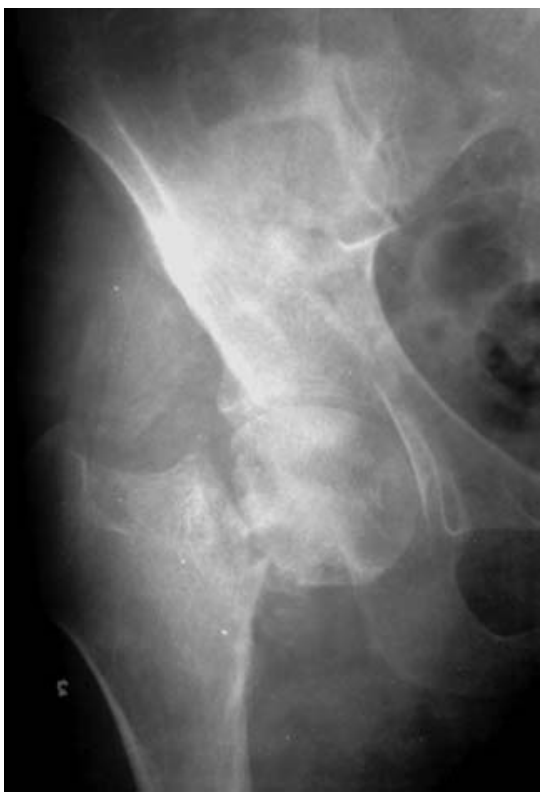

Fig. 3a

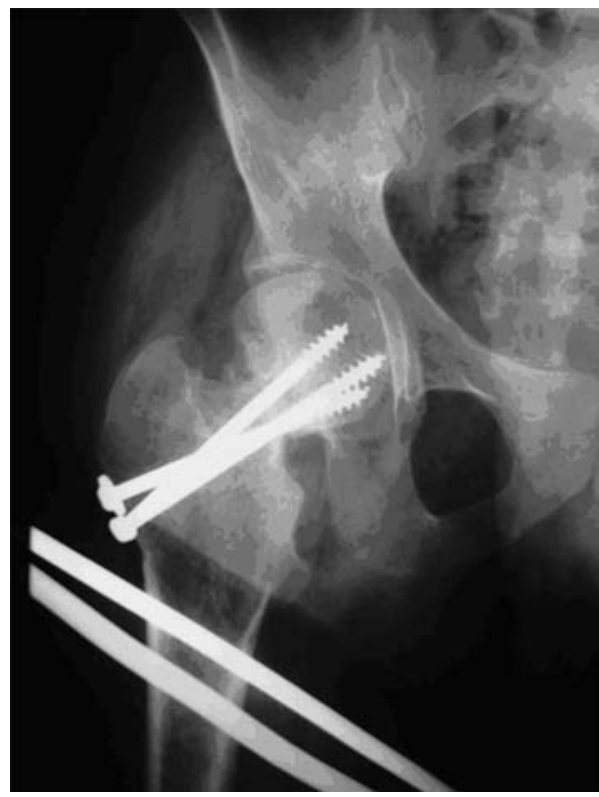

Fig. $3 b$

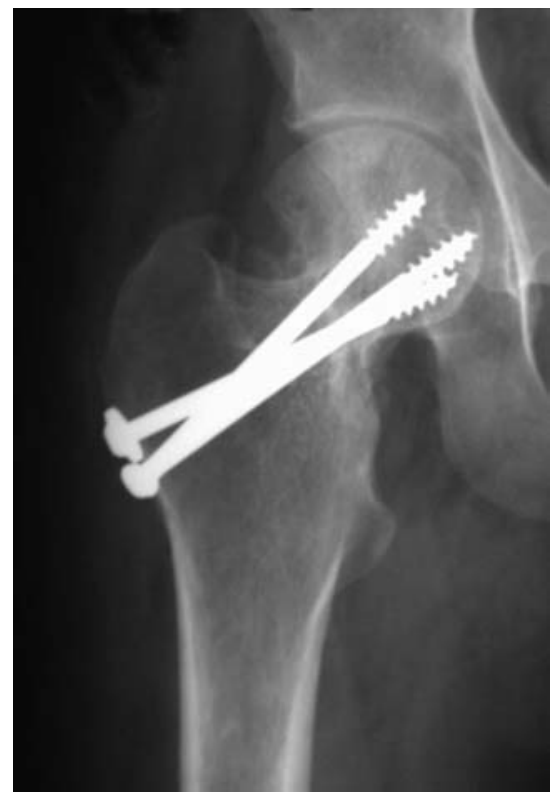

Fig. 3c

Figure $3 \mathrm{a}$ - Pre-operative radiograph of a 27 -year-old male patient with type 1a nonunion of the femoral neck of six months duration and stage $2 \mathrm{c}$ osteonecrosis of the femoral head. Figure $3 \mathrm{~b}$ - Immediate post-operative radiograph showing fracture fixed with three cancellous screws. The fracture surfaces have poor aposition but has added length to the absorbed femoral neck. Figure $3 c$ - Radiograph five months after operation showing sound union with revascularisation of the femoral head.

rating symptoms or radiological signs suggesting progression of the osteonecrosis. One patient (case 8) with preoperative Steinberg stage III osteonecrosis of the femoral head, had sound union of the fracture and excellent revascularisation of the femoral head at three years (Fig. 1) but had developed flattening of the femoral head and secondary osteoarthritis when seen after 12 years. He had no symptoms.

One patient (case 9), with failed primary internal fixation (Fig. 2a), had a radiologically normal femoral head at the time of the reconstructive surgery and united satisfactorily. However, he developed radiological signs of osteonecrosis in the form of increased density of the femoral head approximately eight months after operation (Fig. 2b). This progressed for approximately one year (Fig. 2c), and finally evolved into dense sclerosis involving the whole femoral head. The femoral head had not collapsed at the latest follow-up at ten years (Fig. 2d). He was able to work as a waiter.

Reduction of the fracture held by two $6.5 \mathrm{~mm}$ cancellous screws was lost in one patient (case 5) with proximal migration of the greater trochanter. The fracture, however, united approximately five months post-operatively albeit with coxa vara. Manipulation under general anaesthesia was required approximately ten months after surgery to improve the range of movement of the hip.

One of the three Knowles pins broke in one patient.

\section{Discussion}

The incidence of nonunion following intracapsular fracture of the femoral neck in younger patients may be as high as $59 \% .{ }^{20}$ This is attributed to the high-energy trauma responsible for such injuries. These fractures are often markedly displaced and have a vertical fracture plane, predisposing them to nonunion and osteonecrosis. ${ }^{21}$ It has been described as the unsolved fracture. ${ }^{31}$ In the developing world patients with neglected trauma often present months or even years after injury. In this series only two patients had failed primary internal fixation of the fracture. Ununited fractures due to neglected trauma have their own characteristics, with rounding of the fracture fragments, absorption of the femoral neck and gross overriding of fracture ends resulting in severe shortening of the limb. There is also usually a longstanding contracture of the abductor muscles. It is generally desirable in such cases to apply skeletal traction preoperatively to stretch the contracted soft tissues and restore limb length.

The aim of treatment should be to achieve union with restoration of length of the femoral neck and preservation of vascularisation of the head. Abduction osteotomy not only further shortens the abductor lever arm of the absorbed femoral neck, but compromises any remaining vessels in the ligamentum teres and the joint capsule, thereby increasing the risk of avascular necrosis. ${ }^{32,33}$ The present technique, in an attempt not to further shorten the abductor lever arm, 
often conferred a relatively poor fixation to the fracture with little contact between the uncompressed fracture surfaces (Fig. 3). Therefore all patients were immobilised with some external support for the limb after operation for varying periods. Despite such biomechanical disadvantages as the vertical alignment of the fracture in almost all patients, and the absence of the appositional and compression stability at the fracture surfaces, all patients obtained union with displacement at the fracture site only occurring in one patient after fixation. Such excellent results prove the osteogenic potential of the vascularised periosteal graft.

Haemodynamic studies using positron emission tomography have shown that the femoral head is always in a hypovolaemic state compared with other osseous tissue. ${ }^{34}$ Both the extra- and the intraosseous blood supplies of the femoral head are susceptible to injury in patients with a femoral neck fracture. Although the major intraosseous vessels are nearly always damaged, injury to the extraosseous vessels is proportional to the amount of displacement of the fracture. A dynamic MRI study in patients with Garden stages III and IV $^{33}$ fractures showed that almost all the femoral heads were partially or completely avascular. ${ }^{35}$ Open reduction of a fracture of the femoral neck through a posterior approach has the disadvantage of possible damage to any remaining blood supply from the posterior retinacular vessels and the ascending branch of the medial circumflex femoral artery. However, a hypovolaemic femoral head with further compromise of its blood supply due to the displaced fracture of the femoral neck may not have much to lose in terms of its blood supply during an open reduction.

Free vascularised periosteal grafts have been used, with excellent results not only for treatment of femoral neck fractures, ${ }^{10}$ but also for avascular necrosis of the femoral head, ${ }^{36}$ avascular necrosis of the talus ${ }^{7}$ and nonunion of the clavicle. ${ }^{37}$ In our series the seven patients with pre-operative osteonecrosis of the femoral head showed no further progression, implying that the periosteal graft may augment the local blood supply, although one patient developed avascular necrosis radiologically, but without collapse at ten years.

Muscle pedicle bone grafting may provide live bone at the site of the comminution, ${ }^{38}$ but its efficacy in promoting fracture union has not been found to be comparable with that of other techniques. ${ }^{39}$ Free vascularised grafting, whether of bone or of the periosteum, requires an extended operating time and microvascular expertise, whereas the myoperiosteal flap is technically a much simpler procedure. The myoperiosteal flap has been shown to provide good bone formation for laryngotracheal reconstruction ${ }^{18}$ but has not been used in orthopaedic practice.

Ollier ${ }^{1}$ was the first to demonstrate bone formation in experimental animals using free periosteal grafting. The use of periosteum in clinical practice began in 1965, when Skoog 9 described a maxillary periosteal flap for palatal repair. Burstein and Canalis ${ }^{40}$ established the reliability of bone formation in the vascularised periosteal flap. Osteo- progenitor cells appear by the seventh day and collagen fibre deposition and mineralisation by the ninth day after elevation of the flap. ${ }^{6}$ As early as 72 hours after transposition, cellular and capillary proliferation and osteoid deposition have been identified. ${ }^{41}$ Vascularised periosteum-hydroxyapatite composites have shown bone formation not only on the surface but also in pores of the hydroxyapatite composite at four weeks, further demonstrating its osteogenic capacity. ${ }^{42}$

Varying degrees of absorption of the neck of the femur were seen in all patients. The exact mechanism causing posttraumatic bone loss in the femoral neck is not known. Many hypotheses have been proposed, including a reflex loss of neurovascular tone causing persistent vasodilatation, local change in $\mathrm{pH}$; release of local cytokines or prostaglandins, or even direct mechanical action. ${ }^{43-45}$ Post-traumatic absorption of the femoral neck has been reported to have a very rapid onset, with complete absorption of the neck occurring within less than a month. ${ }^{46,47}$ In the present series three patients had complete absorption of the femoral neck with injuries of six, 16 and 18 months' duration. However, as a result of the delayed presentation it is not known whether absorption was complete within the first month of the injury or progressed over a long period. It is interesting to note that two of the radiological signs of risk of nonunion ' $a$ ' and ' $c$ ', osteonecrosis of the femoral head and complete absorption of the femoral neck, respectively, were not found to co-exist in any of the patients in this series. This observation deserves further exploration.

This report suggests that the presence of osteonecrosis of the femoral head is not incompatible with a satisfactory clinical outcome following reconstructive surgery for ununited fractures of the neck of the femur. Any surgical procedure that facilitates union and is able to postpone replacement surgery for approximately a decade is a useful option for young patients in this situation.

No benefits in any form have been received or will be received from a commercial party related directly or indirectly to the subject of this article.

\section{References}

1. Ollier L. Recherche experimental sur la production artficielle des os an moyen de la transplantation du perioste et sur la regeneration des os après les resection et les ablations completes. J Physiol L'Homme Animaux 1867;2:1-30 (in French).

2. Haldeman KO. The influence of periosteum on the survival of bone grafts. J Bone Joint Surg 1933;15:302-19.

3. Kubota $\mathbf{Y}$, Shirasuna K. The use of free-periosteum for secondary bone grafting to the maxillary alveolar clefts. Ann Plast Surg 2005;55:599-602.

4. McWilliams CA. The function of the periosteum in bone transplants based on four human transplantations without periosteum and some animal experiments. Surg Gynecol Obstet 1914;18:159.

5. Reynders P, Becker JH, Broos P. Osteogenic ability of free periosteal autografts in tibial fractures with severe soft tissue damage: an experimental study. J Orthop Trauma 1999;13:121-8.

6. Burstein FD, Canalis RF, Canclis EM, Ariyan M. Scanning electron microscopy and gel electrophoresis of vascularized periosteal autografts. Plast Reconstr Surg 1989;83:500-10.

7. Doi K, Sakai K. Vascularized periosteal bone graft from the supracondylar region of the femur. Microsurgery 1994;15:305-15.

8. Sakai K, Doi K, Kawai S. Free vascularized thin corticoperiosteal graft. Plast Reconstr Surg 1991;87:290-8.

9. Skoog T. The use of periosteal flaps in the repair of the primary palate. Cleft Palate J 1965;2:332-9. 
10. Zhu SX, Shen YN, Lu SB, Zhang BX, Wang JF. Transposition of iliac periosteum with vascular pedicle and compression screw fixation for transcervical fracture of femur. Chin Med J 1989;102:34-40.

11. Vögelin MDE, Jones NF, Lieberman JR, et al. Prefabrication of bone by use of a vascularized periosteal flap and bone morphogenetic protein. Plast Reconstr Surg 2002;109:190-8.

12. Vogelin E, Jones NF, Huang JI, Brekke JH, Lieberman JR. Healing of a critical-sized defect in the rat femur with use of a vascularized periosteal flap, a biodegradable matrix, and bone morphogenetic protein. J Bone Joint Surg [Am]2005;87-A:1323-31.

13. Baksi DP. Internal fixation of ununited femoral neck fractures combined with musclepedicle bone grafting. J Bone Joint Surg [Br] 1986;68-B:239-45.

14. Meyers MH, Harvey JP Jr, Moore TM. Delayed treatment of subcapital and transcervical fractures of the neck of the femur with internal fixation and muscle pedicle bone graft. Orthop Clin North Am 1974;5:743-56.

15. Baksi DP. Treatment of osteonecrosis of the femoral head by drilling and muscle pedicle bone grafting. J Bone Joint Surg [Br] 1991;73-B:241-5.

16. De SD, Balasubramaniam P. Anterior trochanteric muscle pedicle grafting. J Bone Joint Surg [Br] 1991;73-B:171-2.

17. Li WG, Li YJ, Yun H. A new operation for reconstruction of the femoral neck. J Bone Joint Surg [Br] 1994;76-B:988-90

18. Friedman M, Mayer AD. Laryngotracheal reconstruction in adults with the sternomastoid myoperiosteal flap. Ann Otol Rhinol Laryngol 1993;102:741.

19. Dedrick DK, Mackenzie JR, Burney RE. Complications of femoral neck fracture in young adults. J Trauma 1986;26:932-7.

20. Protzman RB, Burkhalter WE. Femoral neck fractures in young adults. J Bone Joint Surg $[$ Am] 1976;58-A:689-95.

21. Swiontkowski MF, Winquist RA, Hansen ST. Fractures of the femoral neck in patients between the ages of twelve and forty five years. J Bone Joint Surg [Am] 1984;66-A:837-46

22. Ballmer FT, Ballmer PM, Baumgaertel F, Ganz R, Mast JW. Pauwels osteotomy for nonunions of the femoral neck. Orthop Clin North Am 1990;21:759-67.

23. Marti RK, Schullr HM, Raaymakers ELFB. Intertrochanteric osteotomy for nonunion of the femoral neck. J Bone Joint Surg [Br] 1989;71-B:782-7.

24. Wu CC, Shih CH, Chen WJ, Tai CL. Treatment of femoral neck nonunions with a sliding compression screw: comparison with and without subtrochanteric valgus osteotomy. J Trauma 1999;46:312-17.

25. Henderson MS. Ununited fracture of the neck of the femur treated by the aid of the bone graft. J Bone Joint Surg 1940;22:97.

26. Nagi ON, Dhillon MS, Goni VG. Open reduction and internal fixation and fibular autografting for neglected fracture of femoral neck. J Bone Joint Surg [Br] 1998;80 B:798-804

27. Beris AE, Payatakes AH, Kostopoulos VK, et al. Non-union of femoral neck fractures with osteonecrosis of the femoral head: treatment with combined free vascularised fibular grafting and subtrochanteric valgus osteotomy. Orthop Clin North Am 2004;35:335-43.

28. LeCroy CM, Rizzo M, Gunneson EE, Urbaniak JR. Free vascularised fibular bone grafting in the management of femoral neck nonunion in patients younger than fifty years. J Orthop Trauma 2002:16:464-72.
29. Steinberg ME, Breighton CT, Corces A, et al. Osteonecrosis of the femoral head: results of core decompression and grafting with electrical stimulation. Clin Orthop 1989;249:199-208

30. Harris WH. Traumatic arthritis of the hip after dislocation and acetabular fractures: treatment by mold arthroplasty. J Bone Joint Surg [Am] 1969;51-A:737-55.

31. Dickson JA. The 'unsolved' fracture: a protest against defeatism. J Bone Joint Surg [Am] 1953;35-A:805-22.

32. Calandruccio RA, Anderson WF. Post fracture avascular necrosis of the femoral head: correlation of experimental and clinical studies. Clin Orthop 1980;152:49-84.

33. Garden RS. Low angle fixation in fractures of the femoral neck. $J$ Bone Joint Surg [Br] 1961;43-B:647.

34. Nakamura F, Fujioka M, Takahashi KA, et al. Evaluation of the hemodynamics of the femoral head compared with the ilium, femoral neck and femoral intertrochanteric region in healthy adults: measurement with positron emission tomography (PET). Ann Nucl Med 2005;19:549-55.

35. Konishiike T, Makihata E, Tago H, Sato T, Inoue H. Acute fracture of the neck of the femur: an assessment of perfusion of the head by dynamic MRI. J Bone Joint Surg [Br] 1999;81-B:596-99.

36. Zhu SX, Zhou MW. Iliac periosteal graft with vascular pedicle in the treatment of vascular necrosis of the femoral head: experimental study and clinical application. Chin Med J (Engl) 1992;105:849-55.

37. Fuchs B, Steinmann SP, Bishop AT. Free vascularized corticoperiosteal bone graft for the treatment of persistent nonunion of the clavicle. J Shoulder Elbow Surg 2005;14:264-8.

38. Meyers MH. The role of posterior bone grafts (muscle-pedicle) in femoral neck fractures. Clin Orthop 1980;153:143-6.

39. Johnson KD, Brock G. A review of reduction and internal fixation of adult femoral neck fractures in a county hospital. J Orthop Trauma 1989;3:83-6.

40. Burstein FD, Canalis RF. Studies on the osteogenic potential of vascularized periosteum: behaviour of periosteal flaps transferred onto soft tissues. Otolaryngol Head Neck Surg 1985;93:731-5.

41. Canalis RF, Burstein FD, Dickman O, Berke G. Early structural changes in vascularized periosteal flaps studies in situ. Am J Otolaryngol 1991;12:90-5.

42. Ishida H, Tamai S, Yajima H, et al. Histologic and biochemical analyses of osteogenic capacity of vascularized periosteum. Plast Reconstr Surg 1996;97:512-18.

43. Jones GB, Midgley RL, Smith GS. Massive osteolysis: disappearing bones. J Bone Joint Surg [Br] 1958;40-B:494-501.

44. Johnson PM, McClure J. Observations on massive osteolysis: a review of the literature and report of a case. Radiology 1958;71:28-41.

45. Lichtenstein L. Disease of bone and joints. Second ed. St. Louis: Mosby, 1975:242-5

46. Roback DL. Posttraumatic osteolysis of the femoral neck. AJR Am J Roentgenol 1980;134:1243-4

47. Lambiase RE, Levine SM, Froehlich JA. Rapid osteolysis of the femoral neck after fracture. AJR Am J Roentgenol 1999;172:489-91. 